Check for updates

Oxford University Hospitals NHS Trust, Oxford, UK

emily.fraser@ouh.nhs.uk Cite this as: BMJ 2020;370:m3001 http://dx.doi.org/10.1136/bmi.m3001 Published: 03 August 2020

\title{
Long term respiratory complications of covid-19
}

\section{Substantial population morbidity is likely \\ Emily Fraser respiratory consultant}

The extent and severity of the long term respiratory complications of covid-19 infection remain to be seen, but emerging data indicate that many patients experience persistent respiratory symptoms months after their initial illness. ${ }^{1}$ Recently published guidance by the NHS lays out the likely aftercare needs of patients recovering from covid-19 and identifies potential respiratory problems including chronic cough, fibrotic lung disease, bronchiectasis, and pulmonary vascular disease. The evidence for these possible sequelae is largely derived from acute manifestations of covid-19, along with extrapolations from the 2003 outbreak of severe acute respiratory syndrome (SARS) and data on acute respiratory distress syndrome (ARDS). ${ }^{2}$

It is reported that approximately $30 \%$ of people with SARS or Middle East respiratory syndrome had persisting lung abnormalities after their acute illness. ${ }^{2}$ Two prospective studies followed up healthcare workers with nosocomial SARS infection from hospitals in Hong Kong and Beijing for two and 15 years, respectively, and both studies found that persisting impairments in lung function were common. ${ }^{34}$ For most patients, however, these deficits were mild and mostly comprised a modest reduction in gas transfer (to around $70-80 \%$ of the predicted value).

In the Beijing study, 71 patients underwent serial computed tomography from 2003 to 2018 . The presence of parenchymal abnormalities (ground glass opacity and "cord-like consolidation") was seen in 27 patients (38\%), ${ }^{4}$ but after 12 months these generally occupied less than $10 \%$ of the lung. Investigators noted that the degree of functional impairment was disproportionate to the extent of physiological impairment and concluded that muscle weakness due to deconditioning was a contributing factor. ${ }^{3}, 4$

Other studies have investigated the long term effects of ARDS, which is characterised by widespread airspace opacification on computed tomography of the lung. This non-specific manifestation of acute lung injury can be precipitated by a range of injurious stimuli, including severe covid-19. ${ }^{5}$ Although early studies found that survivors often developed substantial lung fibrosis, this was later linked to barotrauma secondary to high pressure ventilation, ${ }^{6}$ and more recent studies (including patients treated with extracorporeal membrane oxygenation) report relatively minor abnormalities. ${ }^{7,8}$

\section{Different demographics}

These findings seem reassuring, but the demographics of patients with severe covid-19 differ from those enrolled in previous longitudinal studies in which few participants were over 45 years and few had comorbidities. Long term outcomes might not be comparable, as many patients admitted to hospital with covid-19 have pre-existing disease and varying degrees of frailty. Risk factors for moderate or severe covid-19 are similar to those of idiopathic pulmonary fibrosis: male gender and older age. ${ }^{9}$ In addition, coronavirus targets alveolar epithelial cells, and evidence implicates other viruses infecting these cells, such as herpes viruses, in the pathogenesis of pulmonary fibrosis. ${ }^{10}$ Cellular changes occurring with ageing such as genomic instability, mitochondrial dysfunction, and epigenetic modification might reduce these cells' ability to respond effectively to viral encounter, triggering pathways that promote both dysregulated repair and fibrosis. ${ }^{11}$

Since inflammation can lead to fibrosis in several forms of interstitial lung disease, treatment often targets inflammation. ${ }^{12}$ High dose steroids were given routinely to many patients with SARS, and this might partly explain the limited incidence of fibrosis observed. ${ }^{3}, 4$ The benefit of dexamethasone in severe covid-19 has recently been established, but treatment did not improve acute outcomes among patients with milder disease. ${ }^{13}$ The longer term implications of steroids in the management of covid-19 have not yet been evaluated but widespread use cannot be recommended due to the substantial morbidity associated with these agents.

Guidelines published by the British Thoracic Society recommend chest radiography three months after discharge for all patients admitted to hospital with covid-19. Those with a history of moderate or severe disease, with persisting symptoms or with radiological abnormalities, require clinical review and further investigation. ${ }^{14}$ The recently launched post-hospitalisation covid-19 study aims to recruit 10 ooo patients in the UK to identify the medical, psychological, and rehabilitation needs of patients admitted to hospital with covid-19 and to provide a comprehensive picture of the longer term effects of infection. ${ }^{15}$

Most patients with covid-19, however, are managed in the community, and management of their persisting symptoms is less straightforward. Chest radiography might be helpful, and patients can be referred to respiratory clinics for investigation of persisting lung abnormalities and thromboembolic disease. There seems to be a fairly poor correlation between symptoms and objective measures of disease (author's observation). Fatigue, exercise intolerance, and poor concentration can be particularly problematic. Unfortunately, optimal management remains unclear. An integrated multidisciplinary approach involving doctors, physiotherapists, and 
psychotherapists is likely to be needed, but many UK centres have yet to establish these services, which will probably have limited resources.

To summarise, persistent respiratory complications following covid-19 may cause substantial population morbidity, and optimal management remains unclear. Prospective studies are under way to evaluate these complications further and to identify people at greatest risk. Meanwhile, a pragmatic approach to primary care management might include first line investigations such chest radiography and oxygen saturation measurements, with referral to secondary care where lung pathology needs investigation. Integrated support from a broader primary care team should be considered for patients with more complex symptoms, including those with disproportionate functional impairment.

Provenance and peer review: Commissioned; not peer reviewed.

Competing interests: The BMJ has judged that there are no disqualifying financial ties to commercial companies. The authors declare the following other interests: none.

1 Asthma UK, British Lung Foundation. Post-covid hub. https://www.post-covid.org.uk/get-support/

2 NHS England. Aftercare needs of inpatients recovering from COVID-19. Jun 2020.

https://www.england.nhs.uk/coronavirus/publication/after-care-needs-of-inpatients-recoveringfrom-covid-19/

3 Ngai JC, Ko FW, Ng SS, To KW, Tong M, Hui DS. The long-term impact of severe acute respiratory syndrome on pulmonary function, exercise capacity and health status. Respirology 2010;15:543-50. doi: 10.1111/j.1440-1843.2010.01720.x pmid: 20337995

4 Zhang P, Li J, Liu H, etal. Long-term bone and lung consequences associated with hospital-acquired severe acute respiratory syndrome: a 15 -year follow-up from a prospective cohort study. Bone Res 2020;8:8. doi: 10.1038/s41413-020-0084-5 pmid: 32128276

5 Fan E, Beitler JR, Brochard L, etal. COVID-19-associated acute respiratory distress syndrome: is a different approach to management warranted?Lancet Respir Med 2020;.pmid: 32645311

6 Desai SR, Wells AU, Rubens MB, Evans TW, Hansell DM. Acute respiratory distress syndrome: CT abnormalities at long-term follow-up. Radiology 1999;210:29-35. doi: 10.1148/radiology.210.1.r99ja2629 pmid: 9885583

7 Wilcox ME, Patsios D, Murphy G, etal. Radiologic outcomes at 5 years after severe ARDS. Chest 2013;143:920-6. . doi: 10.1378/chest.12-0685 pmid: 23187463

8 Lindén VB, Lidegran MK, Frisén G, Dahlgren P, Frenckner BP, Larsen F. ECMO in ARDS: a long-term follow-up study regarding pulmonary morphology and function and health-related quality of life. Acta Anaesthesiol Scand 2009:53:489-95.

doi: 10.1111/j.1399-6576.2008.01808.x pmid: 19226296

9 Raghu G, Collard HR, Egan JJ, etalATS/ERS//RS/ALAT Committee on Idiopathic Pulmonary Fibrosis. An official ATS/ERS/IRS/ALAT statement: idiopathic pulmonary fibrosis: evidence-based guidelines for diagnosis and management. Am J Respir Crit Care Med 2011;183:788-824. doi: 10.1164/rccm.2009-040GL pmid: 21471066

10 Tang YW, Johnson JE, Browning PJ, etal. Herpesvirus DNA is consistently detected in lungs of patients with idiopathic pulmonary fibrosis. J Clin Microbiol 2003;41:2633-40. doi: 10.1128/JCM.41.6.2633-2640.2003 pmid: 12791891

11 Lawson WE, Crossno PF, Polosukhin VV, etal. Endoplasmic reticulum stress in alveolar epithelial cells is prominent in IPF: association with altered surfactant protein processing and herpesvirus infection. Am J Physiol Lung Cell Mol Physiol 2008;294:L1119-26. doi: 10.1152/ajplung.00382.2007 pmid: 18390830

12 Meyer KC. Diagnosis and management of interstitial lung disease. Transl Respir Med 2014;2:4. . doi: 10.1186/2213-0802-2-4 pmid: 25505696

13 Horby P, Lim WS, Emberson J, et al. Effect of dexamethasone in hospitalized patients with covid-19: preliminary report. MedRxiv 20202020.2006.2022.20137273 [Preprint] https://www.medrxiv.org/content/10.1101/2020.06.22.20137273v1.

14 British Thoracic Society. Guidance on respiratory follow up of patients with a clinico-radiological diagnosis of covid-19 pneumonia. 2020. www.brit-thoracic.org.uk

15 PHOSP-COVID. Improving long-term health outcomes. https:/www.phosp.org/.

This article is made freely available for use in accordance with BMJ's website terms and conditions for the duration of the covid-19 pandemic or until otherwise determined by BMJ. You may use, download and print the article for any lawful, non-commercial purpose (including text and data mining) provided that all copyright notices and trade marks are retained. 